\title{
Evaluating Self Healing Capability of Bituminous Mastics
}

\author{
J. Qiu • M. van de Ven $\cdot$ S. Wu $\cdot$ J. Yu • A. Molenaar
}

Received: 8 March 2011 / Accepted: 9 November 2011 /Published online: 13 December 2011

(C) The Author(s) 2011. This article is published with open access at Springerlink.com

\begin{abstract}
The self-healing capability of bituminous materials has been known for many years. Researches were mostly focused on the self healing behaviour during load repetitions. The tests are either time consuming and/or complex. In this paper, a simple self healing test procedure is presented combining the fracture-healing-re-fracture test (FHR) with morphological observations. A fast displacement speed loading was applied first to produce a flat open crack with a crack width of $100-200 \mu \mathrm{m}$. Then the specimen was placed in a silicone rubber mould to heal. Various healing periods, temperatures and material modifications were applied. Fluorescence microscopy was used to observe the morphological change during the healing periods. After healing, the specimen was re-fractured under the same condition as the original fracture test. The experimental results indicate that the self healing capability, which was quantified by the re-fracture strength, increases with increasing healing time and increasing healing temperature. A strength recovery master curve at any healing temperature can be obtained through a timetemperature superposition principle. When comparing the strength recovery master curve with the morphological
\end{abstract}

J. Qiu $(\bowtie) \cdot$ M. van de Ven $\cdot$ A. Molenaar

Road and Railway Engineering, Faculty of Civil Engineering and

Geosciences, Delft University of Technology,

2600GA Delft, The Netherlands

e-mail: j.qiu@tudelft.nl

J. Qiu

e-mail: pidqiu@hotmail.com

J. Qiu $\cdot \mathrm{S} . \mathrm{Wu} \cdot$ J. Yu

Key Laboratory of Silicate Materials Science Engineering of Ministry of Education, Wuhan University of Technology, Wuhan 430070, China healing observation from fluorescence microscopy, the healing process observed in this paper is believed to be a viscosity driven process, consisting of two steps namely crack closure and strength gain. A StyreneButadiene-Styrene polymer modified bituminous mastic shows lower healing capability than a standard 70/100 penetration grade bituminous mastic. The test procedure proposed in this paper is proven to be simple and effective for evaluating and comparing the self healing capability of bituminous materials.

Keywords Self healing $\cdot$ Bitumen $\cdot$ Mastic $\cdot$ Strength $\cdot$ Polymer modification

\section{Introduction}

The self healing capability of bituminous materials has been known for many years [1, 2]. Various healing investigations were carried out to qualify and quantify this phenomenon. It is known that self healing capability is a quite complex phenomenon, which is dependent on different factors including healing time, healing temperature, crack phases, material modifications and confinement. Different approaches have been developed, such as the discontinuous fatigue test with different rest period/load period ratio [3], the fatigue-healing-refatigue test $[4,5]$, the intrinsic two-piece healing test $[6,7]$ and the fracture involved healing test $[8,9]$. For details of these approaches the reader is referred to the literature review made by Qiu [10]. Most of the time, the self healing capability is investigated with the fatigue test with healing rest periods, which is very complex and time consuming. Hence, there is a need to evaluate the self healing capability in a simple and effective way. 
Hammoum and Millard developed a simple repeated local fracture test to investigate the self healing properties of pure bitumen $[8,11]$. The bitumen binder was held between two hemispheric protuberances simulating two aggregates into the asphalt mix. All the tests were carried out at $0^{\circ} \mathrm{C}$. A displacement controlled tension loading was applied to the system with a displacement speed of $12.5 \mu \mathrm{m} / \mathrm{s}$ for $4 \mathrm{~s}$. After loading, the system moved back to the initial gap-thickness between the spheres. Then healing of possible cracks was carried out with healing time intervals of $2 \mathrm{~min}$ and $2 \mathrm{~h}$. During the healing period, a slight compressive load of $50 \mathrm{~N}$ was applied on the sample holder. After the healing period, the loading was applied again. After $2 \mathrm{~h}$ healing, the bitumen could almost recover to its original fracture property regarding the loading and the reloading curve.

The authors of this paper performed investigations on self healing capability of different types of bitumen using a direct tension test (DTT) [9]. A dog-bone shape direct tension bituminous sample made from a silicone rubber mould was cut into two equal parts with a sharp knife at $5^{\circ} \mathrm{C}$. Then the two cut surfaces were brought into contact with each other, placed into the silicone rubber mould and stored at room temperature (around $22^{\circ} \mathrm{C}$ ) for $3,6,20$ and $48 \mathrm{~h}$. After the healing period, the strength was determined in a DTT test at $0^{\circ} \mathrm{C}$ at a displacement speed of $10 \mathrm{~mm} / \mathrm{min}$. It was shown that after $6 \mathrm{~h}$ healing periods at room temperature, the strength was recovered to the value of the original undamaged specimen.

Hence, the fracture involved healing test procedure seems promising to investigate the self healing capability of bituminous materials in a simple and effective way. However, the methods proposed in the literature were too empirical. Neither of the test methods gives clear information on the crack situation, which is believed to be important for quantifying the self healing capability. In order to describe the cracked situation, a microscopy observation was added to the fracture-healing-re-fracture procedure (FHR). The usefulness of this new procedure for the evaluation of the self healing capability of bituminous mastic will be described in this paper.

\section{Experimental}

\section{Materials}

Two types of bituminous binders were used in this research:

- A standard 70/100 penetration grade Kuwait Petroleum bitumen with a penetration of $93(0.1 \mathrm{~mm})$ at $25^{\circ} \mathrm{C}$, and a softening point of $45^{\circ} \mathrm{C}$;

- A Styrene-Butadiene-Styrene (SBS) polymer modified bitumen from Shell with a penetration of $65(0.1 \mathrm{~mm})$ at $25^{\circ} \mathrm{C}$, and a softening point of $70^{\circ} \mathrm{C}[12]$.

Bituminous mastics were produced by mixing the bituminous binders with a Wigro limestone filler with a mass ratio of $1: 1$. In this paper, the mastic with the $70 / 100$ penetration bitumen is called PBmas, and with the SBS polymer modified bitumen is called SBSmas. Master curves of the complex modulus and the phase angle of the PBmas and the SBSmas at a reference temperature of $0^{\circ} \mathrm{C}$ are shown in Fig. 1 .

\section{Test Procedure}

The FHR tests were carried out using a Direct Tension Test Machine (ATS 900DTTS) with a temperature chamber. The experimental procedure is discussed below and also shown in Fig. 2:
Fig. 1 Master curves of the PBmas and the SBSmas at a reference temperature of $0^{\circ} \mathrm{C}$

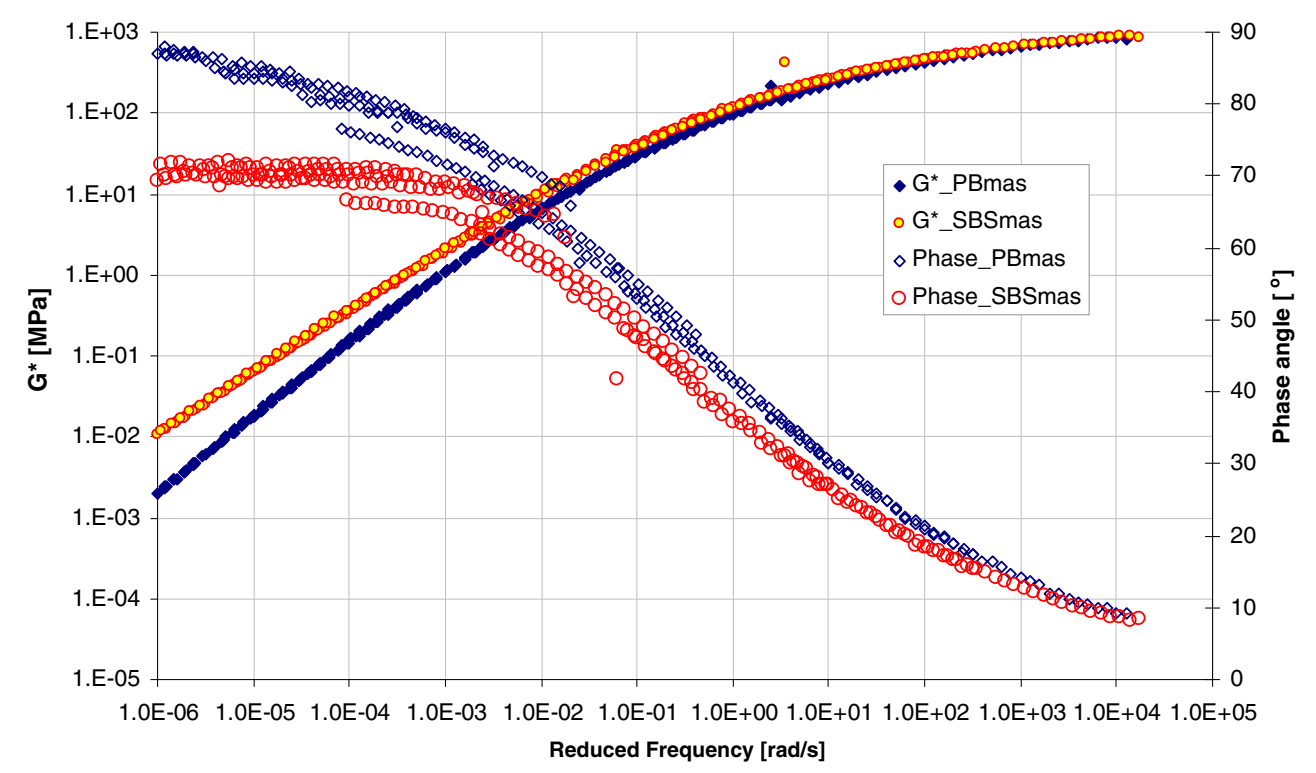


Fig. 2 Illustration of the FHR test procedure

Fig. 3 Illustration of placing the two broken pieces (left) into the silicone rubber mould (right)

Fig. 4 Illustration of special specimen geometries (from top to bottom: DTT, DN, DP)

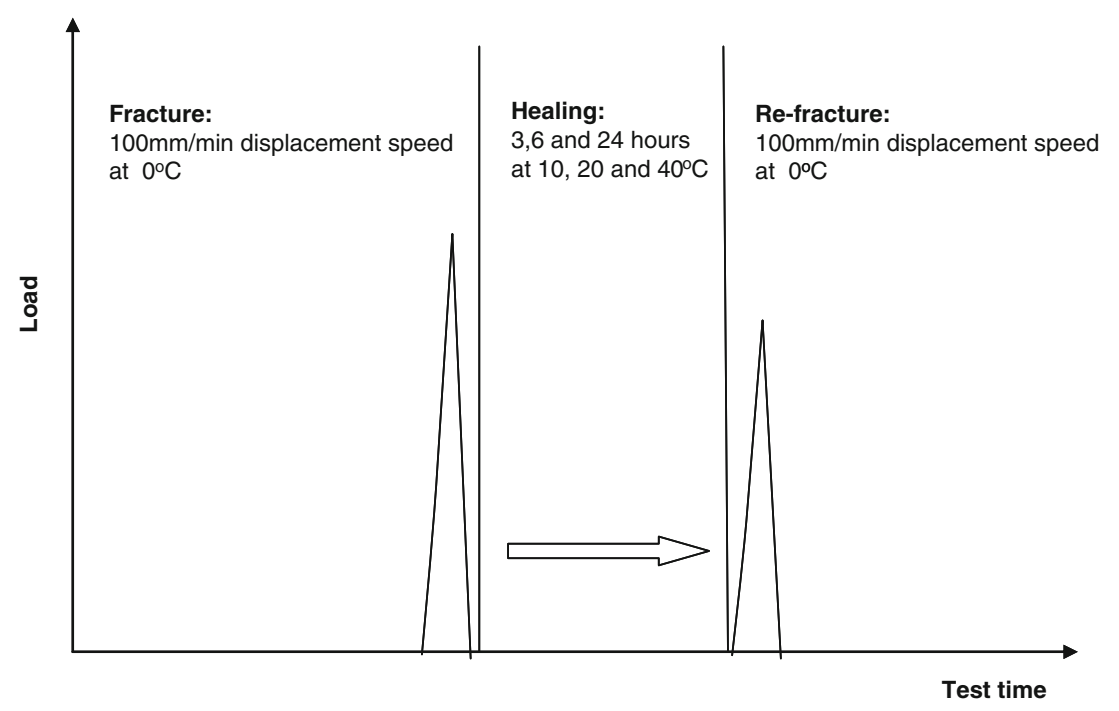

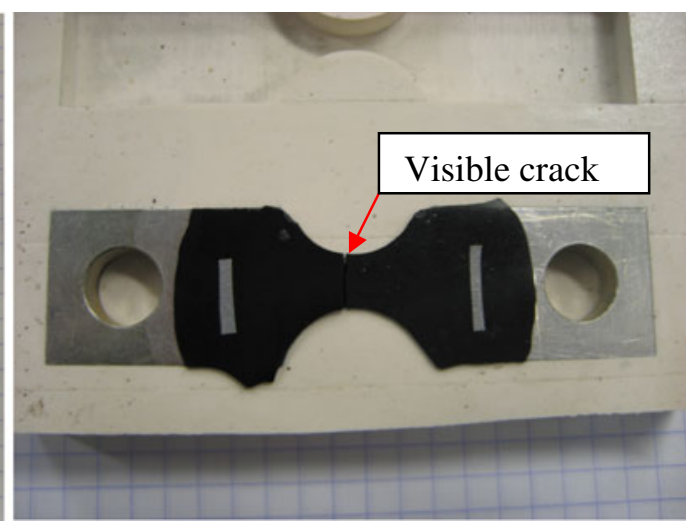

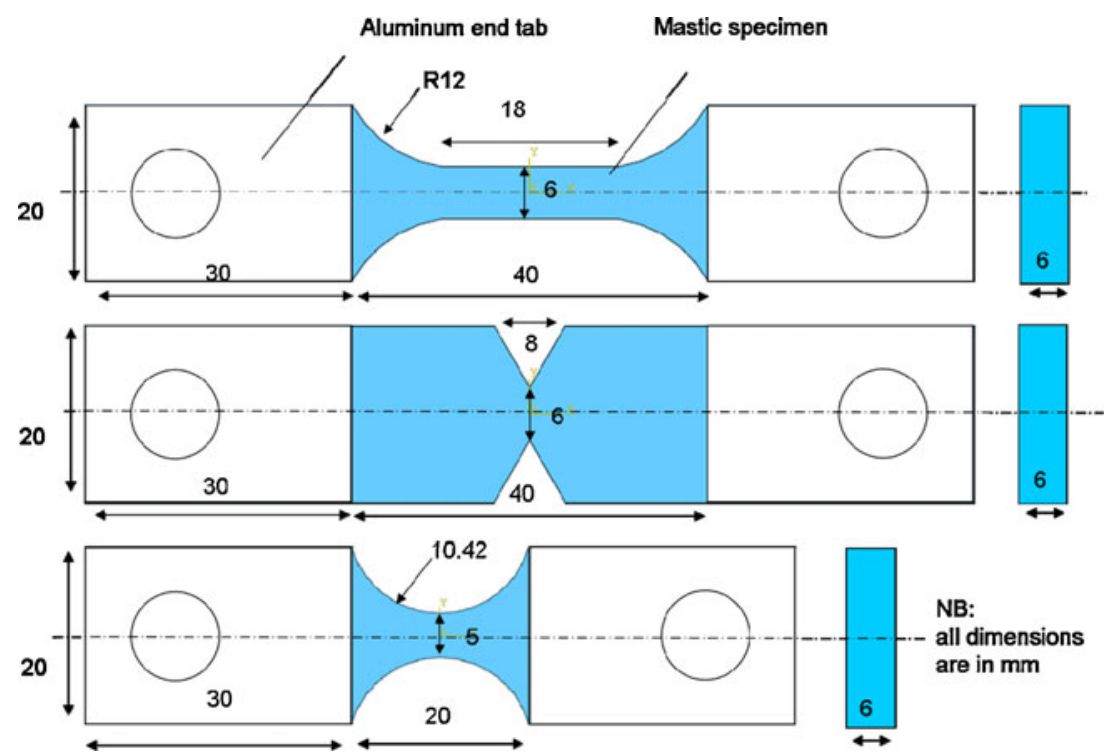


Fig. 5 ABAQUS simulation of the special specimen geometries (from top to bottom: DTT, DN, DP)

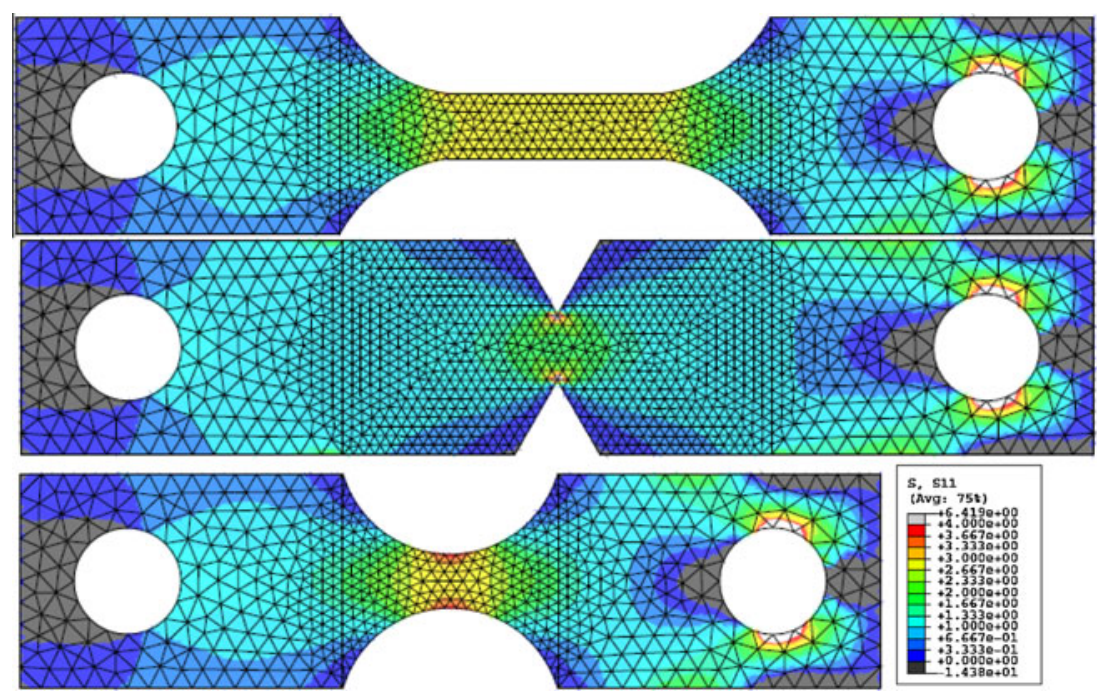

- Preparation. Before the FHR test, the samples were made in a preheated silicone rubber mould, and covered with another piece of preheated silicone rubber in order to get the same texture at each side of the specimen and to avoid the temperature effect on samples [13]. After cooling in the refrigerator, the samples were de-moulded and placed in the temperature chamber of the DTT machine for at least $2 \mathrm{~h}$ at $0^{\circ} \mathrm{C}$.

- Fracture. The original samples were fractured using a displacement speed of $100 \mathrm{~mm} / \mathrm{min}$ at $0^{\circ} \mathrm{C}$.

- Healing. The two broken pieces of the specimen were placed back into the silicone rubber mould to heal. Due to the limited deformation of the sample after failure, the two broken pieces fit nicely into the mould with a visible crack as it is shown in Fig. 3. Various healing temperatures of $10^{\circ} \mathrm{C}, 20^{\circ} \mathrm{C}$ and $40^{\circ} \mathrm{C}$ and healing periods of $3 \mathrm{~h}, 6 \mathrm{~h}$ and $24 \mathrm{~h}$ were applied for both the PBmas and the SBSmas.

- Microscopy observation. An Olympus Fluorescence Microscopy was also used to investigate the morphological change of the sample during the healing period at ambient temperature (around $25^{\circ} \mathrm{C}$ ). The observation times were $0,1,3,8$ and $18 \mathrm{~h}$.

- Re-fracture. After the healing periods, the specimens were conditioned back to $0^{\circ} \mathrm{C}$ for at least $2 \mathrm{~h}$ and then de-moulded. The specimens were re-fractured afterwards with a displacement speed of $100 \mathrm{~mm} / \mathrm{min}$ at $0^{\circ} \mathrm{C}$.

The self healing percentage was calculated by the refacture strength of the healed sample divided by fracture strength of the original sample:

$H=\frac{S_{\text {refracture }}}{S_{\text {fracture }}} \times 100 \%$
Where,

$\mathrm{H} \quad$ is the self healing percentage

$\mathrm{S}_{\text {refracture }}$ is the strength of the re-fractured samples

$\mathrm{S}_{\text {fracture }} \quad$ is the strength of the original fractured samples.

\section{Results and Discussions}

Specimen Geometry

Prior to the FHR test, special attention was given to the geometry of the specimen. Previous healing tests were done with a standard DTT specimen [9]. However, the DTT specimens were shown to be not suitable for self healing investigations because of the following reasons. Firstly, a sudden break of the normal DTT specimens during the fracture test would cause the sample to break into more

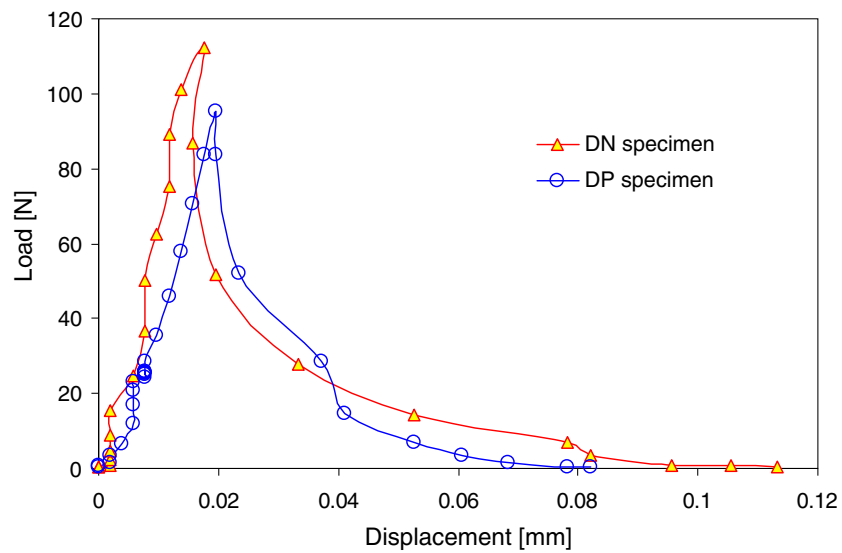

Fig. 6 Test results of the PBmas specimens with different geometries at a displacement speed of $100 \mathrm{~mm} / \mathrm{min}$ at a temperature of $0^{\circ} \mathrm{C}$ 
Fig. 7 Illustration of broken surface of samples after $100 \mathrm{~mm} / \mathrm{min}$ (left) and $10 \mathrm{~mm} / \mathrm{min}$ loading (right)
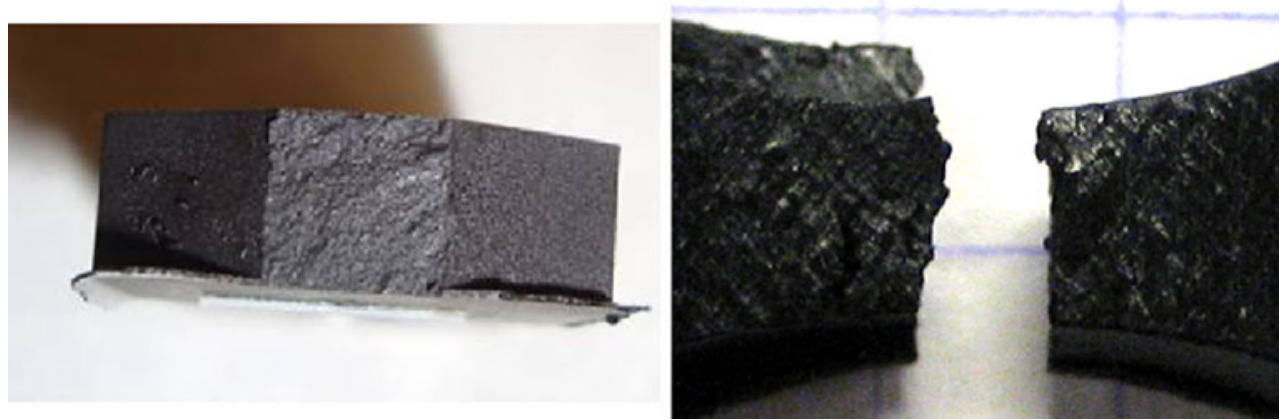

than two pieces, making further healing and re-fracture impossible. Secondly, in order to get an indication of the healing of the crack, the re-fracture surface was supposed to be the same as the fracture surface. However, sometimes the re-fractured sample did break at a different place than the first fracture surface, which caused variable results. Hence, there is a need for a special specimen geometry for self healing investigations.

As it is shown in Fig. 4, inspired by fracture-mechanics based fracture tests reported in literature [14-16], specimens were developed with a stress concentrated shape. Two types of stress concentrated specimens were developed namely a double-edge notched shaped specimen (DN) and a double-edge parabolic shaped specimen (DP). A standard dog-bone shaped DTT specimen was used for comparison.

Figure 5 shows the stress concentration ratio of the developed specimens via Finite Element Modelling [17]. For simplicity, an elastic modulus of $50 \mathrm{MPa}$ and a possion's ratio of 0.45 were arbitrarily chosen and assigned to the bituminous mastics. A tension load of $100 \mathrm{~N}$ was applied. The stress concentration in the middle of the DN and DP specimen can clearly be observed. However, for a standard DTT sample geometry, the stress distribution in the middle part is almost constant, which makes it not possible to predict the breaking point. This can also explain why the standard DTT sample could break into more than two pieces in a fracture test.

After several trials, a displacement speed of $100 \mathrm{~mm} / \mathrm{min}$ at a temperature of $0^{\circ} \mathrm{C}$ was chosen for the fracture test condition. Figure 6 shows the fracture curves of different geometries for a displacement speed of $100 \mathrm{~mm} / \mathrm{min}$ at a temperature of $0^{\circ} \mathrm{C}$. The DN specimen and the DP specimen show similar fracture behaviour. However, in practice, the de-moulding of the DN specimen from the silicone rubber mould is very difficult. Because of its high stress concentration in the notch, it can be damaged easily during de-moulding. While the DP specimen showed a much better workability.

In Fig. 7, the failed specimens with different displacement speeds are compared. The sample suddenly breaks in the middle with a displacement speed of $100 \mathrm{~mm} / \mathrm{min}$ because of stress concentration. However, the specimen which was tested at a displacement speed of $10 \mathrm{~mm} / \mathrm{min}$ shows alligator shape cracks in the middle of the specimen. The micro cracks and macro cracks are initiated and propagated all in the sample instead of a sudden break.
Fig. 8 Self healing test results of the PBmas and the SBSmas

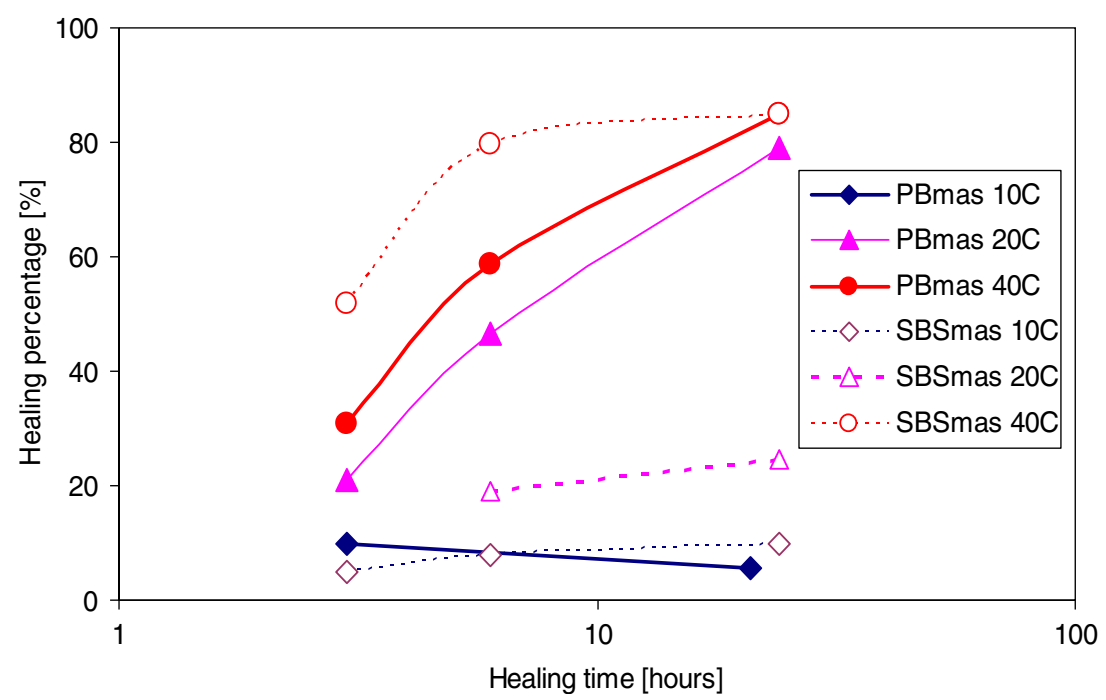


Fig. 9 Self healing master curves of the re-fracture strength of the bituminous mastics at a reference temperature of $20^{\circ} \mathrm{C}$

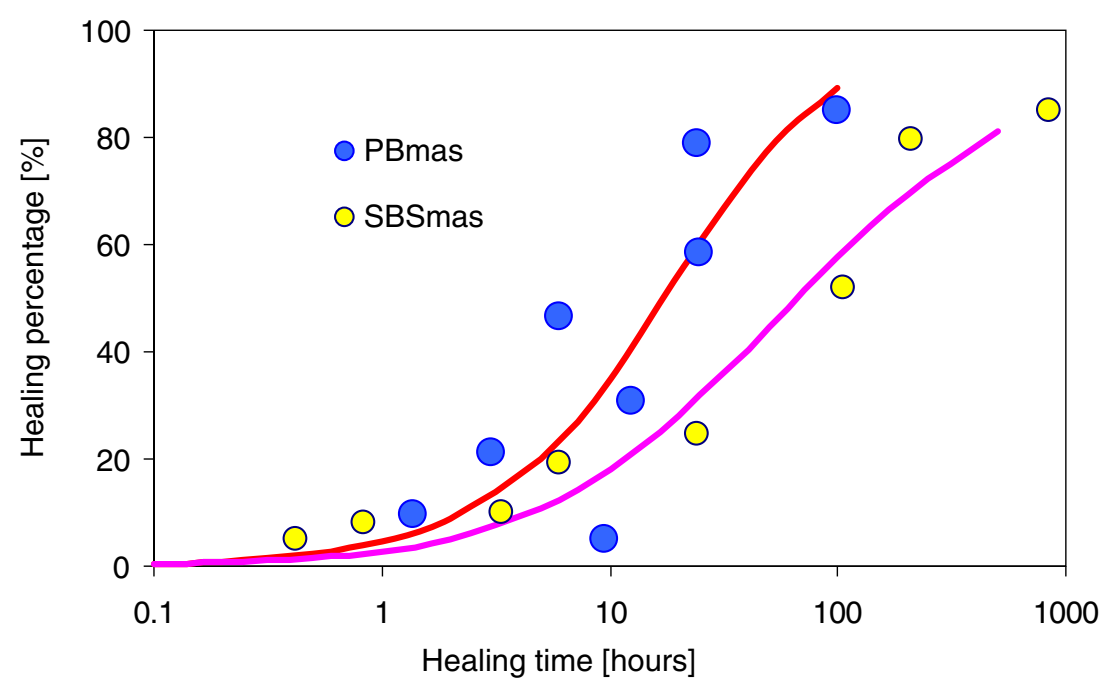

As a result, the DP specimen with a displacement speed of $100 \mathrm{~mm} / \mathrm{min}$ at a temperature of $0^{\circ} \mathrm{C}$ was used in the FHR test.

\section{Strength Recovery}

Figure 8 shows the FHR test results of the PBmas and the SBSmas. As bituminous materials indicate timetemperature dependency, such feature can also be observed for the self healing process. The healing percentage increases with increasing healing time and increasing healing temperature. The following observations can be made when comparing the healing speed of the PBmas and the SBSmas. The healing percentage of both the PBmas and the SBSmas is only $10 \%$ after healing at $10^{\circ} \mathrm{C}$. The PBmas shows faster healing at a temperature of $20^{\circ} \mathrm{C}$ and $40^{\circ} \mathrm{C}$, which approaches nearly $80 \%$ after a healing period of $24 \mathrm{~h}$. The SBSmas shows a limited healing ability at $20^{\circ} \mathrm{C}$ but a fast healing speed at $40^{\circ} \mathrm{C}$.

To model the time-temperature dependency of the self healing process, a strength recovery master curve was constructed using a time-temperature superposition principle. An S shaped equation was used as shown in equation (2), which was similar to the Christensen-Anderson Model for the complex modulus master curves of bituminous binders [18, 19]. The time-temperature superposition shift factor in equation (3) is based on the Arrhenius Equation.

$$
\begin{aligned}
& H(t, T)=100 \times\left[1+\left(\frac{m}{t \times \alpha_{T}}\right)^{\frac{\log 2}{n}}\right]^{\frac{n}{\log 2}} \\
& \log \alpha_{T}(T)=\frac{\Delta E_{a}}{2.303 R}\left(\frac{1}{T}-\frac{1}{T_{0}}\right)
\end{aligned}
$$

Where:

$\alpha_{T} \quad$ is the time-temperature superposition shift factor $\mathrm{m}, \mathrm{n}$ are the model parameters

$\Delta E_{a}$ is the apparent activation energy, $\mathrm{J} / \mathrm{mol}$

$\mathrm{R} \quad$ is the universal gas constant, $8.314 \mathrm{~J} /(\mathrm{mol} \cdot \mathrm{K})$.

Figure 9 shows the strength recovery master curves of both the PBmas and the SBSmas at a reference temperature of $20^{\circ} \mathrm{C}$. The related model parameters are shown in Table 1. It is shown that the PBmas could approach $100 \%$ healing in much less time than the SBSmas.

\section{Morphological Observation}

Figure 10 shows the cross-section of the PBmas and the SBSmas after fracture. The SBSmas has clearly shining spots in the cross-section compared to the PBmas, which are believed to be the broken SBS molecules. The SBS molecules cover about $25 \%$ of the surface area according to the statistical analysis of the photo.

Figure 11 presents the morphological measurement of the PBmas at different healing times. The crack is about $150 \mu \mathrm{m}$, and the closure of the crack can clearly be monitored over time. After a healing period of $3 \mathrm{~h}$, the crack disappears because of the full closure of the crack.

Table 1 List of model parameters

\begin{tabular}{llll}
\hline & $\mathrm{m}[$ hours $]$ & $\mathrm{n}[-]$ & $\Delta$ Ea $[\mathrm{J} / \mathrm{mol}]$ \\
\hline PBmas & 22.22 & 0.24 & 124749 \\
SBSmas & 32.3 & 0.44 & 312195 \\
\hline
\end{tabular}


Fig. 10 Fluorescence microscopy of the cross-section of the PBmas (left) and the SBSmas (right)
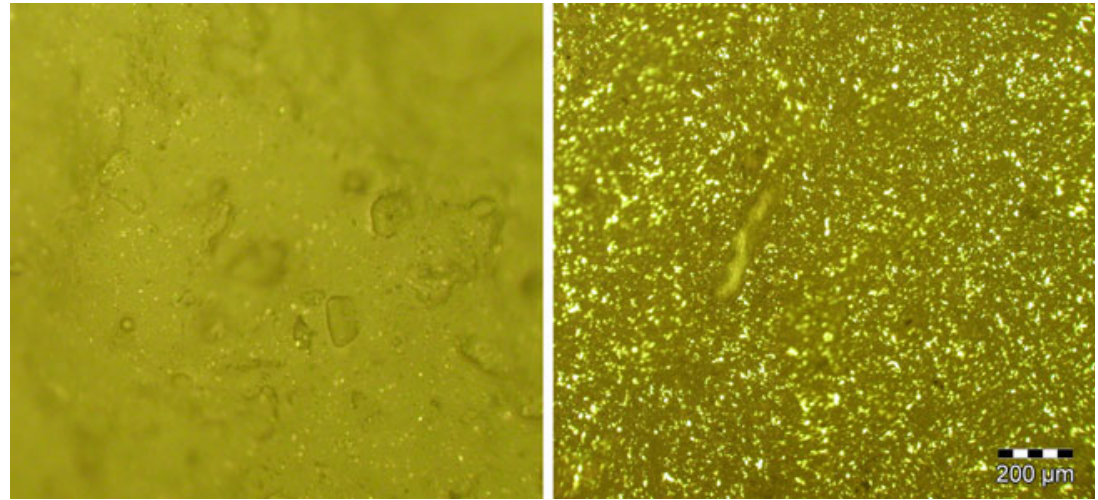

Figure 12 shows the morphological measurement during the healing process of the SBSmas. The crack is initially about $100 \mu \mathrm{m}$. It is interesting to see that the crack closure speed is much less compared to the PBmas sample. After a healing time of $8 \mathrm{~h}$, a crack can still be observed.

Figure 13 compares the development of the crack sizes with the recovery of the re-fracture strength. In Fig. 13, two phases can be observed namely crack closure and strength gain. It is observed that the full closure of the crack does not mean a total recovery of the re-fracture strength. Once the crack is closed, the bituminous samples may still have micro cracks and air bubbles inside the sample which are not easy to be detected. Further healing time is still needed for the strength gain of the specimen. Hence, the nature of the bituminous binder has a huge influence on the healing process. The healing in this crack phase is believed to be a viscosity driven process [13].

When comparing the two different mastics the PBmas and the SBSmas used in this research, the PBmas shows excellent healing capability in both crack closure phase and strength gain phase. The SBS polymer modification gives a significant improvement of the high temperature and low temperature properties of bituminous binders because of the polymer network. However, the network also absorbs soft components from the bitumen, resulting in a bitumen with a high viscosity. That could be the reason why the SBSmas shows a lower healing speed. In addition, as it is known, the SBS molecules are stable at the test temperatures from $10^{\circ} \mathrm{C}$ to $40^{\circ} \mathrm{C}$, implying that no phase change or physical chemical reactions will happen at these temperatures. Thus the broken SBS molecules can not repair themselves during
Fig. 11 Fluorescence microscopy of the PBmas specimen with different healing times $(0,1,3$ and $18 \mathrm{~h})$
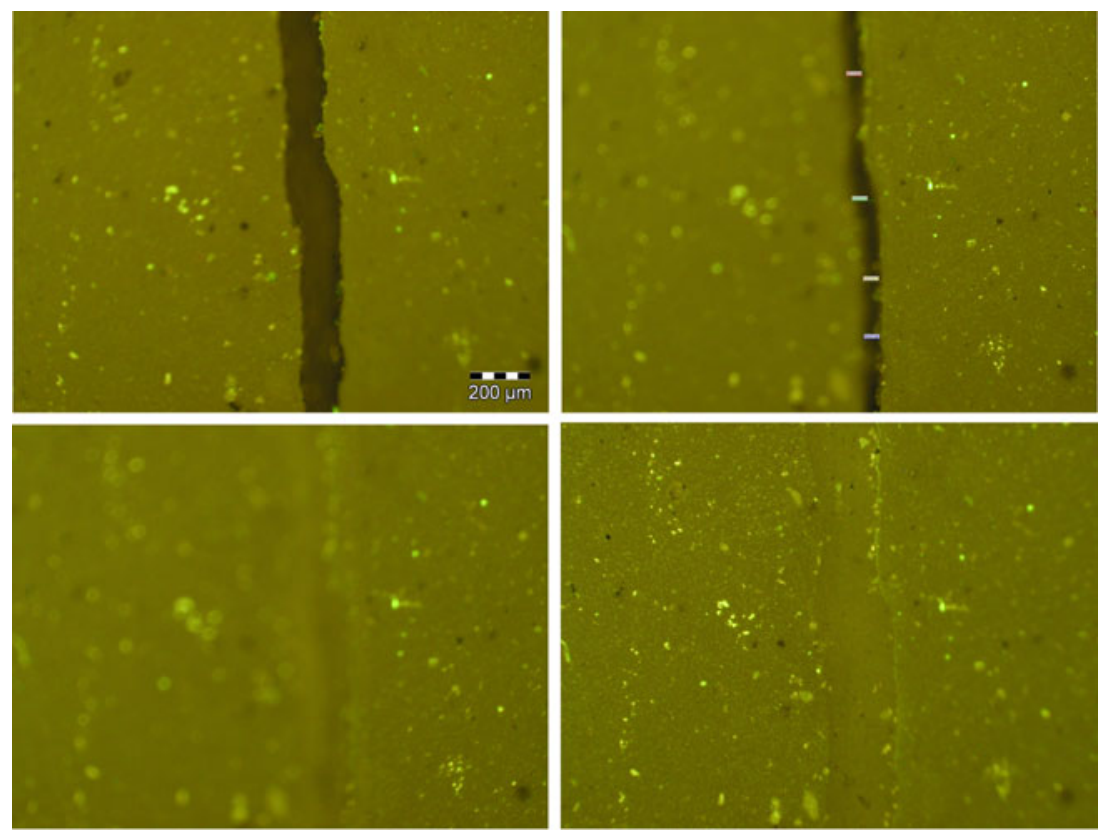

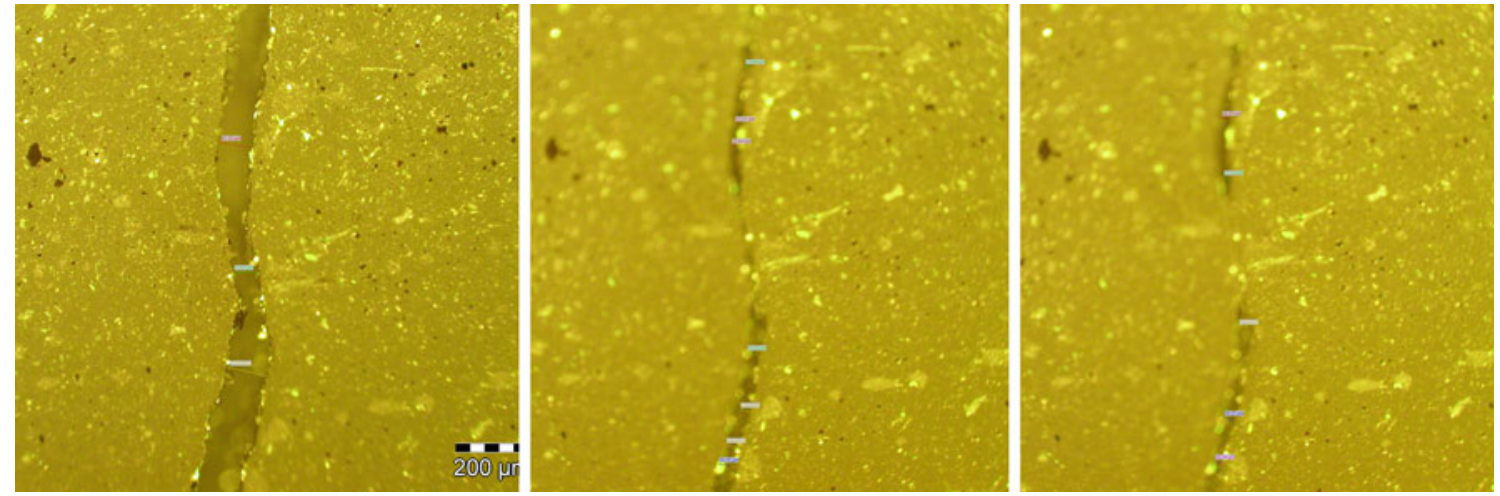

Fig. 12 Fluorescence microscopy of the SBSmas specimen with different healing times $(0,3$ and $8 \mathrm{~h})$

the healing process, and will act as a "filler" in the bituminous system. Moreover, the broken SBS molecules cause difficulties for wetting and inter-diffusion during the healing process. But this influence is lower at a higher temperature. All these reasons add up to a lower healing speed of the SBSmas.

\section{Conclusions and Recommendations}

The self healing capability of bituminous mastics has been investigated using a microscopy coupled fracture-healingre-fracture test procedure. Based on the test data and analysis, the following conclusions can be made:

a. The test procedure is proven to be capable to evaluate the self healing capability of an open crack in a simple and effective way.

b. A strength recovery master curve can be obtained with the time-temperature superposition principle. c. Healing of an open crack is believed to be a viscosity driven process. The healing process includes two phases: crack closure and strength gain. The completion of the crack closure process does not imply a full recovery of the strength.

d. The negative effect of the polymer modification on the self healing capability can be observed clearly. An SBS modified bituminous mastic shows a lower self healing capability than a standard 70/100 penetration bituminous mastic in both crack closure and strength gain phase.

In the future, the research will be focused on further implementation of the simple test procedure for the development of new self healing components and to compare the self healing capabilities of different types of bituminous materials. In addition, instead of evaluating the intrinsic self healing capability of bituminous materials, this simple test procedure can also be applied for evaluating the crack-sealing capability of sealant and joint materials.
Fig. 13 Comparison of the crack closure process and the strength recovery process at a temperature of $25^{\circ} \mathrm{C}$

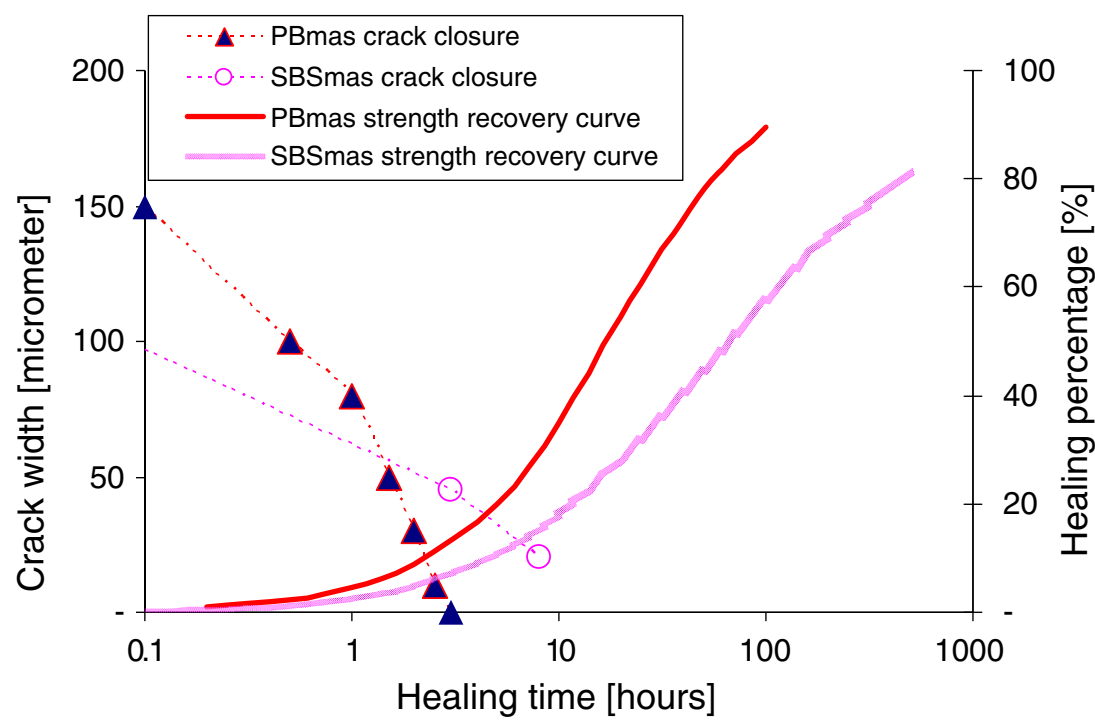


Acknowledgement The first author would like to thank the China Scholarship Council for the financial contributions. The authors appreciate the cooperation between Wuhan University of Technology and Delft University of Technology and express their wish to prolong and strengthen the current cooperation between the mentioned institutes of technology. Discussions and suggestions offered from Dr. Liantong Mo and Mr. Ad Pronk were highly appreciated. The authors also thank the reviewers for their valuable discussions and suggestions.

Open Access This article is distributed under the terms of the Creative Commons Attribution Noncommercial License which permits any noncommercial use, distribution, and reproduction in any medium, provided the original author(s) and source are credited.

\section{References}

1. Van Dijk W, Moreaud H, Quedeville A, Uge P (1972) The fatigue of bitumen and bituminous mixes. Paper presented at the $3 \mathrm{rd}$ int. Conference on the Structural Design of Asphalt Pavements, Ann Arbor, Michigan, USA

2. Francken L (1979) Fatigue performance of a bituminous road mix under realistic best conditions. Transp Res Rec 712:30 34

3. Shen S, Chiu H-M, Huang H (2010) Characterization of fatigue and healing in asphalt binders. J Mater Civ Eng 22(9):6

4. Phillips MC (1998) Multi-step models for fatigue and healing, and binder properties involved in healing. Paper presented at the Eurobitume Workshop on Performance Related Properties for Bituminous Binders, Luxembourg

5. Shan L, Tan Y, Underwood S, Kim YR (2010) Application of thixotropy to analyze fatigue and healing characteristics of asphalt binder. Paper presented at the 2010 Annual Meeting of the Transportation Research Board

6. Bhasin A, Little DN, Bommavaram R, Vasconcelos K (2008) A framework to quantify the effect of healing in bituminous materials using material properties. Road Mater Pavement Des EATA2008:219-242

7. Qiu J, van de Ven MFC, Wu SP, Yu JY, Molenaar AAA (2011) Investigating self healing behaviour of pure bitumen using dynamic shear rheometer. Fuel 90(8):2710-2720

8. Hammoum F, de La Roche C, Piau JM (2002) Experimental investigation of fracture and healing of bitumen at pseudo-contact of two aggregates. Paper presented at the 9th International Conference on Asphalt Pavements

9. Qiu J, Van de Ven MFC, Wu SP, Yu JY, Molenaar AAA (2009) Investigating the self healing capability of bituminous binders. Road Mater Pavement Des 10(SI):81-94

10. Qiu J (2008) Self healing of asphalt mixes: literature review. Report 7-08-183-1. Delft University of Technology, Delft

11. Maillard S, De La Roche C, Hammoum F, Gaillet L, Such C (2004) Experimental investigation of fracture and healing of bitumen at pseudo-contact of two aggregates. Paper presented at the 3 rd Eurasphalt \& Eurobitume Congress, Vienna

12. SHELL (2003) Productinformatie 1539NL01 Cariphalte XS. Shell Nederland Verkoopmaatschappij B.V

13. Muraya PM (2007) Permanent deformation of asphalt mixes. Delft University of Technology

14. Erkens SMJG (2002) Asphalt concrete response (ACRe)-determination, modeling and prediction. Delft University of Technology

15. Hesp SAM (2004) An improved low-temperature asphalt binder specification method. Final Report, MTO Contract No. 9015-A-000190 and NCHRP-IDEA Contract No. 84. Kingston, Ontario

16. Hesp SAM (2006) Development of an improved asphalt binder specification testing approach. Final Report for Highway IDEA Project 104. Kingston, Ontario

17. ABAQUS (2006) ABAQUS user's manual, Version 6.6.

18. Christensen DW, Anderson DA (1992) Interpretation of dynamic mechanical test data for paving grade asphalt caments. J Assoc Asph Paving Technol 61:67-116

19. Woldekidan M, Huurman M, Mo L (2010) Testing and modeling of bituminous mortar response. J Wuhan Univ Technol-Mater Sci Ed 25(4):637-640. doi:10.1007/s11595-010-0060-9 